\title{
Approaching patient engagement in research: what do patients with cardiovascular disease think?
}

This article was published in the following Dove Press journal:

Patient Preference and Adherence

27 July 2015

Number of times this article has been viewed

\section{Lila J Finney Rutten ${ }^{1,2}$ \\ Megan A Morris ${ }^{1,2}$ \\ Lisa M Schrader' \\ Sheila M Manemann² \\ Jyotishman Pathak ${ }^{1,2}$ \\ Robert Dimler ${ }^{3}$ \\ Veronique L Roger ${ }^{1,2}$}

'Robert D and Patricia E Kern Center for the Science of Health Care

Delivery, Mayo Clinic, Rochester, MN, USA; ${ }^{2}$ Department of Health Sciences Research, Mayo Clinic, Rochester MN, USA; ${ }^{3}$ The Rochester Coronary Club, Inc., Rochester MN, USA
Correspondence: Lila J Finney Rutten Mayo Clinic, 200 First Street SW, Rochester, MN 55905, USA

$\mathrm{Tel}+$ I 507293234 I

Fax +I 5075387957

Email rutten.lila@mayo.edu

\begin{abstract}
Movement toward patient-centered health care must be supported by an evidence base informed by greater patient engagement in research. Efforts to better understand patients' interest in and perspectives on involvement in the research process are fundamental to supporting movement of research programs toward greater patient engagement. We describe preliminary efforts to engage members of a community group of patients living with heart disease to better understand their interest and perspectives on involvement in research. A semi-structured focus group guide was developed to probe willingness to participate in the following three phases of research: preparation, execution, and translation. The focus group discussion, and our summary of key messages gleaned from said discussion, was organized around the phases of research that patients may be involved in, with the goal of delineating degrees of interest expressed for engagement in each phase. Consistent with what is known from the literature, a clear preference for engagement during the preparation and translation phase of the research process emerged. This preliminary conversation will guide our ongoing research efforts toward greater inclusion of patients throughout the research process.
\end{abstract}

Keywords: patient engagement, phases of research, patient-centered care, research translation

\section{Patient-centered care and patient engagement in research}

Health care reforms calling for greater focus on disease prevention, health promotion, and shared decision-making, coupled with a fundamental shift in health care from episodic acute care to chronic disease management, create unprecedented opportunities to re-center health care on patients and their needs and preferences. Patient-centered care is responsive to the values, preferences or wants, and expressed needs of the patient with sensitivity to patients' cultural and social values. ${ }^{1-3}$

In parallel to the patient-centered movement in health care delivery, increasing attention and resources have been devoted to engaging patients in the research process, based on the notion that patient engagement in designing, implementing, and disseminating research will facilitate translation of research into clinical practice to improve the value of research for patients. ${ }^{4-11}$ The science of health care delivery emerges here at the intersection of research and practice, and is squarely focused on building the evidence base for best practice, which includes a keen focus on patient experiences and preferences. It has been argued that patient engagement in research, to better understand the questions and outcomes of relevance to patients, is crucial to inform patient-centered care. ${ }^{12,13}$ 
A recent systematic review of existing evidence, commissioned by the Patient Centered Outcomes Research Institute, summarizes strategies for identifying and engaging patients in research, and describes common related benefits and barriers. This review organized research engagement into three phases of research: 1) preparatory phase, involving agenda setting and research prioritization; 2) execution phase, involving development of study design, methods, and analytic approach; and 3) translation phase, involving evaluation and implementation and dissemination of results. ${ }^{14}$

As investigators pursue greater patient involvement in their own research efforts, it is essential to connect with relevant patient groups to better understand their needs and preferences with regard to engagement in the various phases of research. As a preliminary step in this direction, in February of 2015, we conducted a focus group discussion around patient engagement in research with members of a community group of patients living with heart disease, with the intent to inform our plans for engaging patients in our ongoing program of research in cardiovascular epidemiology. Traditionally, epidemiological research is somewhat removed from the patient experience. However, with the growing recognition of the important role that patients can play in defining relevant research questions, implementing research in a patient-centered fashion, and providing an organic network for dissemination of research findings, there is movement toward greater patient engagement. Herein we describe our preliminary experiences with patient engagement to showcase an example for other investigators starting on this path, to highlight the value of patient engagement, and share patients' perspective on involvement in research efforts.

We brought a series of questions around patient engagement in the various phases of research to the Rochester Coronary Club, Inc. (RCC), a standing community-based support organization for patients and families affected by heart disease. Developed under an American Heart Association grant in 1979, RCC encourages heart patients to reach their full potential by supporting patients and families through normalization and education. In addition to unstructured time for fellowship, monthly meetings are comprised of formal presentations and open discussions with experts in heart health. This has included cardiologists and internists as well as dieticians, nutritionists, exercise physiologists, pharmacists, and psychologists. Chaired by a community member with no medical certification or education, the RCC board consists of both lay community members and employees from the local medical centers serving cardiac patients. Patients and families are made aware of RCC during cardiac related in- and outpatient visits via word of mouth and a brochure listing local and national cardiovascular support resources, and monthly postcards and email reminders are sent to those who have expressed interest. Approximately 40 members attend RCC meetings each month.

During the February 2015 monthly meeting of the RCC, one of our study team members provided an overview of the focus group topic and individuals were offered the chance to participate. Potential participants indicated their interest by leaving their name and contact information with study personnel. Ten individuals participated in the focus group, which was held in March, 2015. Information regarding the purpose and goals of the focus group was shared with participants upon arrival, and participation consent was verified and documented. A qualitative research expert on our team facilitated the focus group using questions and prompts from a semi-structured interview guide. Questions and discussion focused on how participants may wish to be involved in the planning, conduct, and dissemination of research related to their medical condition(s), as well as how they feel others affected by cardiovascular disease may wish to be engaged. Discussion was transcribed in real-time by communication access real-time translation and summarized by our research team. Focus group responses were reviewed independently within each question series (planning, conduct, and dissemination of research) and consistent themes and notable comments were identified.

\section{Patients' perspective on involvement in research}

Herein, we share a summary of our discussion with members of RCC, which provides insight into patients' perspectives on and interest in involvement in research efforts. The focus group involved ten (five female, five male) adults actively involved in RCC. Half of the participants were aged 41-60 years; the remaining were aged 61 years or older. The majority of participants described themselves as non-Hispanic white. A semi-structured focus group guide was developed that probed for willingness to participate in the three phases of research described in the aforementioned systematic review. The themes identified in review of the focus group discussion centered on the phases of research that patients may be involved in. We summarize these themes herein, with the goal of delineating degrees of interest expressed for engagement in each phase.

\section{Preparation phase}

Participants expressed eagerness and willingness to engage with researchers in the preparation phase of research studies. Several participants discussed concerns that research topics were not necessarily patient-centered nor reflected needs of 
patients. Consequently, they were interested in providing input on research topics to ensure that the research questions and outcomes were relevant and meaningful to patients. As one participant stated:

I don't think there's been a great deal of patient involvement in research. [...] if it's going to be for the patient, how you do it and what you look for should be information provided by the patient.

The participants easily described a range of research questions that they believed as important and relevant. Examples of topics included understanding the long-term effects of cardiac medications, using genetics to identify populations at risk for heart disease, and exploring sex difference in cardiac rehabilitation attendance. Additionally, participants thought that research studies should include a diverse study sample.

\section{Execution phase}

In contrast to the preparation phase, participants had a harder time conceptualizing what their role could be in the execution phase of a research study. Participants were unaware of how study participants are typically recruited. They reported being willing to assist in recruiting study participants if they were provided appropriate support and guidance. When given the example of possibly interviewing subjects for a qualitative study or as a part of a survey, the focus group participants expressed a willingness to assist, but this was not an activity they have experience with.

\section{Translation phase}

Participants expressed a dedication and willingness to assist in dissemination of research findings to both patients and the scientific community. Many of the participants actively participate in educating others about heart disease. For example, several discussed sharing their story of heart disease at faithbased organizations or with patients in the clinical setting. They shared ideas of how to disseminate research findings through these avenues. The participants were adamant that an important part of dissemination was translating the research findings into language that could be easily understood by patients. As one participant stated:

Sometimes when people write research, other people don't understand it. It's helpful to edit it just to make sure you understand what the people are trying to say.

The participants stated a willingness to assist in this process.

Several of the participants expressed a desire to participate in scientific meetings and assisting with presentations, but the cost of attending a scientific meeting is often prohibitive. One participant described his experience participating in a scientific meeting positively:

I was sent to a four-day, national conference on patientfamily centered care. It was an amazing educational opportunity to be there with other patients and many well-known medical people. And I think for us to be able to have that opportunity without a $\$ 500$ bill, it would be wonderful.

A solution discussed was integrating into grant budgets the cost of attending conferences for patient stakeholders.

\section{Conclusion}

The RCC is a highly engaged group of patients who have been actively involved in research previously. They admitted that their willingness to engage in the research process might not be representative of all patients. Regardless, they represent an important patient voice and could greatly enhance the patient-centeredness of the research process. Specifically, our conversation with members of the RCC sheds valuable light on how and when we might engage with patients to inform our program of research moving forward. Overall, participants were actively engaged in the conversation, suggesting a general interest in being involved with research matters. Consistent with what is known from the literature, ${ }^{5}$ members revealed greater understanding for engagement during the preparation and translation phase of the research process. As the conversation revealed opportunities for engagement in the implementation phase of research, members seemed to show greater understanding for involvement in this phase of research, underscoring the importance of pursuing these kinds of discussions very early in the research process.

This preliminary conversation will guide our ongoing efforts toward greater inclusion of patients throughout the research process. In continued partnership with this organization, we will be able to vet research ideas, engage interested members in active involvement in research implementation, and develop effective strategies for meaningful dissemination of research findings. As health care continues toward greater patient-centeredness and integration with health care delivery research, authentic patient engagement in the research process will ensure prioritization of research efforts to meet patients' needs and to pave a more ready path to translate research findings into improved patient care.

\section{Acknowledgments}

This effort was supported by the Robert D and Patricia E Kern Center for the Science of Health Care Delivery Research and funding from R01 HL 120859. 


\section{Disclosure}

The authors report no conflicts of interest in this work.

\section{References}

1. American Academy of Family Physicians. Joint principles of the PatientCentered Medical Home. Del Med J. 2008;80(1):21-22.

2. Frampton S, Guastello S, Brady C, et al. Patient Centered Care Improvement Guide. Picker Institute; 2008.

3. Epstein RM, Fiscella K, Lesser CS, Stange KC. Why the nation needs a policy push on patient-centered health care. Health Aff (Millwood). 2010; 29(8):1489-1495.

4. Sullivan P, Goldmann D. The Promise of Comparative Effectiveness Research. JAMA. 2011;305(4):400-401.

5. Domecq JP, Prutsky G, Elraiyah T, et al. Patient engagement in research: a systematic review. BMC Health Serv Res. 2014;14:89.

6. Concannon TW, Fuster M, Saunders T, et al. A Systematic Review of Stakeholder Engagement in Comparative Effectiveness and Patient-Centered Outcomes Research. J Gen Intern Med. 2014;29(12):1692-1701.

7. Concannon TW, Meissner P, Grunbaum JA, et al. A new taxonomy for stakeholder engagement in patient-centered outcomes research. $J$ Gen Intern Med. 2012;27(8):985-991.
8. Elwyn G, Crowe S, Fenton M, et al. Identifying and prioritizing uncertainties: patient and clinician engagement in the identification of research questions. J Eval Clin Pract. 2010;16(3):627-631.

9. Forsythe LP, Frank L, Walker KO, et al. Patient and clinician views on comparative effectiveness research and engagement in research. J Comp Eff Res. 2015;4(1):11-25.

10. Mullins CD, Abdulhalim AM, Lavallee DC. Continuous patient engagement in comparative effectiveness research. JAMA. 2012; 307(15):1587-1588.

11. Vandigo J, Oloyede E, Abdulhalim AM, Mullins CD. Continuous patient engagement in comparative effectiveness research (CER): an application in cardiovascular disease (CVD). Value Health. 2014; 17(3):A206

12. Mann MK. Partnering With Patients to Help Heal Healthcare. CircCardiovasc Qual. 2013;6(6):613-614.

13. Tinetti ME, Basch E. Patients' responsibility to participate in decision making and research. JAMA. 2013;309(22):2331-2332.

14. Shippee ND, Domecq Garces JP, Prutsky Lopez GJ, et al. Patient and service user engagement in research: a systematic review and synthesized framework. Health Expect. Epub 2013 Jun 3.

\section{Publish your work in this journal}

Patient Preference and Adherence is an international, peer-reviewed, open access journal that focuses on the growing importance of patient preference and adherence throughout the therapeutic continuum. Patient satisfaction, acceptability, quality of life, compliance, persistence and their role in developing new therapeutic modalities and compounds to optimize clinical outcomes for existing disease states are major areas of interest for the journal. This journal has been accepted for indexing on PubMed Central. The manuscript management system is completely online and includes a very quick and fair peer-review system, which is all easy to use. Visit http://www dovepress.com/testimonials.php to read real quotes from published authors. 